\title{
DOES HEALTH WORKER SUPPORT IMPROVE TREATMENT ADHERENCE IN TUBERCULOSIS PATIENTS DURING THE COVID-19 PANDEMIC?: A SYSTEMATIC REVIEW
}

\author{
Ni Nyoman Elfiyunai, Nursalam \\ Faculty Of Nursing Sciences, Universitas Airlangga, Indonesia
}

\begin{abstract}
Background: Tuberculosis is one of the ten leading causes of death in the world. The duration of TB treatment is 6 to 8 months which requires discipline and social support. Health workers need support to provide motivation, health information, and follow-up of TB treatment during the COVID-19 pandemic to help improve TB treatment adherence. One form of support is through communication tools using the telephone or SMS reminder messages. This study aimed to provide an overview of whether social support from health workers by telephone can help to improve treatment adherence of TB patients during the COVID-19 pandemic.

Subjects and method: This study was a systematic review conducted by using three electronic databases, including Scopus, PubMed, and Science Direct. The dependent variable was TB patient medication adherence. The independent variable was social support from health workers by telephone. The keywords used were "Tuberculosis" AND "Health Workers" AND "Message Reminder" AND "Medication Adherence". The iclusion criteria were full-text articles written in English, published between 2015 and 2021. The selection of articles used PRISMA flow diagram. The total of 235 articles were identified. Results: A total of six articles from Northwest Ethiopia, Cameroon, Anhui Province of China, Rural Uganda, India, Africa, and Pakistan was selected for this study. The social support provided by health workers using cell phones can help to motivate TB patients for treatment adherence, especially for the patients without having someone for reminder or the patient is far from family. The support of health workers using mobile phones can also help to reduce the spread of COVID-19 between health workers and patients during the pandemic time.

Conclusion: Social support from health workers using the telephone is quite effective to increase the patient compliance in treatment during the COVID-19 pandemic. It can reduce the rate of dropouts and forgetness of taking medication, and can increase the patient awareness about the importance of maintaining health during the COVID-19 pandemic.
\end{abstract}

Keywords: tuberculosis, social support, health worker, COVID-19, telephone

\section{Corresponding:}

Ni Nyoman Elfiyunai. Faculty Of Nursing Sciences, Universitas Airlangga, Indonesia. Jl. Otto Iskandar Dinata 76C, East Besusu, East Palu 94111, Central Sulawesi, Indonesia. Email: ni.nyoman.elfiyunai-2020@fkp.unair.ac.id. Mobile: 085241230800. 